\title{
Online trust: a stakeholder perspective, concepts, implications, and future directions
}

\author{
Venkatesh Shankar ${ }^{\mathrm{a}, *}$, Glen L. Urban ${ }^{\mathrm{b}}$, Fareena Sultan ${ }^{\mathrm{c}}$ \\ ${ }^{a}$ Robert H. Smith School of Business, University of Maryland, College Park, MD 20742, USA \\ ${ }^{\mathrm{b}}$ Sloan School of Management, MIT, Cambridge, MA, USA \\ ${ }^{\mathrm{c} C o l l e g e}$ of Business Administration, Northeastern University, Boston, MA 02115 USA
}

\begin{abstract}
Online trust is important in both business-to-business and business-to-consumer e-business. Consumers and businesses, feeling the pressure of economic downturn and terrorism, increasingly look to buy from and do business with organizations with the most trusted Web sites and electronic networks. Companies' perception of online trust has steadily evolved from being a construct involving security and privacy issues on the Internet to a multidimensional, complex construct that includes reliability/credibility, emotional comfort and quality for multiple stakeholders such as employees, suppliers, distributors and regulators, in addition to customers. Further, trust online spans the end-to-end aspects of e-business rather than being just based on the electronic storefront. Based on a review of selected studies, we propose a stakeholder theory of trust, articulate a broad conceptual framework of online trust including its underlying elements, antecedents, and consequences, and propose some promising future research avenues in online trust. This paper will help information systems professionals better understand the online trust perspectives of multiple stakeholders, the antecedents and consequences, thereby enabling them to build more trustworthy Web sites.

(C) 2002 Elsevier Science B.V. All rights reserved.
\end{abstract}

Keywords: e-Commerce; e-Business; Trust; Privacy; Security; Relationship management

\section{Introduction}

Online trust, a reliance on a firm by its stakeholders with regard to its business activities in the electronic medium, and in particular, its Web site, is important in both business-tobusiness (B2B) and business-to-consumer (B2C) e-business. A Forrester survey in 2000 found that $51 \%$ of companies would not do business with parties they do not trust over the Web (Forrester Report, 2000). Lack of trust is one of the greatest barriers inhibiting online

\footnotetext{
* Corresponding author.

E-mail address: vshankar@rhsmith.umd.edu (V. Shankar).
} 
trade between buyers and sellers who are unfamiliar with one another (Jupiter Consumer Survey Report: Retail, 2001). Consumers, feeling the pressure of economic downturn and terrorism, bought mostly from the most trusted sites during the 2001 holiday season (BusinessWeek, 2001). Online trust continues to be important as customers and other stakeholders such as employees, suppliers, distributors and regulators now have access to more information and options on the Web, making it critical for firms to earn and retain the trust of their current or potential customers and other stakeholders. Firms can no longer afford to exploit market inefficiency and uninformed customers. Therefore, understanding how online trust is created and maintained can lead to improved Web sites, sales revenues, profitability, and ultimately shareholder value.

Companies' view of online trust has evolved over time (Hoffman et al., 1999; Sultan et al., 2002). When the first Web sties were created, the companies that created them viewed online trust as a construct that dealt with Web-site security-the issue of whether a user can feel safe to give his/her credit card and other financial details on the company's Web site (Ernst and Young Report, 1999). Subsequently, companies' perception of online trust started to include privacy issues - the issue of how comfortable users felt about giving personal information (Hoffman et al., 1999). Today, trust has become much larger than security and privacy on the Web. It is a multidimensional, complex construct that has important antecedents and consequences (Sultan et al., 2002).

Online trust is also intertwined with offline trust. It is important for firms to understand how online trust is different from offline trust, how the two are interconnected and how to improve online trust and overall firm performance. This is particularly important for organizations that have both online as well as offline presence, that is, multichannel organizations.

Online trust spans the end-to-end aspects of e-business than being just based on the electronic storefront. Online trust is broader than Web-site trust explored by some studies (Yoon, 2002) that are largely focused on the perspective of customers. It extends beyond Web site to all electronic networks used by firms. Online trust is relevant for multiple stakeholders, including customers, employees, suppliers, distributors, partners, stockholders, and regulators. Organizations need a clear understanding of online trust from the standpoints of multiple stakeholders. By knowing the needs of different stakeholders, firms can be in better position to balance these needs and work toward superior firm performance.

Organizations also benefit from a thorough knowledge of the drivers and consequences of online trust so that they can better build and manage online trust with multiple stakeholders. Managers are interested in designing better Web sites and electronic networks that have high levels of trust. A deeper understanding of the factors that drive online trust and the associated outcomes can help them better allocate their resources to trust development and management activities.

In light of the framing of online trust from multiple stakeholders, the following questions are important. What exactly is online trust? How is online trust different from offline trust? How is online trust different for different stakeholders of a firm? What are the underlying dimensions of online trust? What are the antecedents of online trust? What are the consequences of online trust? How can companies build and maintain online trust that is balanced from the perspectives of multiple stakeholders? What are some promising 
areas for future research on online trust? In this paper, we address these questions. We review selected studies, propose a stakeholder perspective of online trust, articulate a broad conceptual framework of online trust including its underlying elements, antecedents and consequences, and suggest some promising research avenues in the area of online trust.

\section{Online trust, offline trust and e-business strategy}

In simple terms, trust can be defined as the belief by one party about another party that the other party will behave in a predictable manner (Luhmann, 1979). Two important elements of trust by a focal party about the other party are: (1) the perception of uncertainty and vulnerability by the focal party in dealing with the other party and (2) the expectation that the other party will behave in the interest of the focal party or in good will (Rousseau et al., 1998; Whitener et al., 1998). It should, however, be noted that the perception of uncertainty and risk is not necessarily widely held. For example, Mayer et al. (1995) propose a model in which perceived risk is a moderator of the relationship between trust and risk-taking. Trust has been extensively studied in accounting, communication, computer science, information systems, management, marketing, philosophy, psychology, and political science since the 1950s. Although each field has its own definition(s), they all have contributed to a better understanding of trust in general.

e-Business strategy is about using the electronic medium (mainly the Internet) to revise business model, rearchitect, redesign, reposition, and remarket the firm for competitive advantage in the digital environment. To this end, online trust may be a critical component of a firm's e-business strategy (Urban et al., 2000). Therefore, it is important to study online trust in great depth to formulate sound e-business strategy.

Two types of trust exist: (1) offline trust that involves the offline activities of the firm (such as direct sales, channel sales, and other communication and transactions) and its relationships with its customers and other stakeholders and (2) online trust that involves the firm's business activities in the electronic medium, and in particular, its Web site. Although online trust is similar to offline trust in many ways, there are some important distinctions. In offline trust, the object of trust is typically a human or an entity (organization). In online trust, typically, the technology (mainly the Internet) itself is a proper object of trust (Marcella, 1999). In a sense, a firm's Web site is its salesperson that needs to build trust with her/his customers (Jarvenpaa et al., 1999). There is, however, some degree of commonality of trust elements and transfer of trust between the online and offline environments. These areas of commonality may include product quality and firm reputation.

With the emergence of multiple touch point or multichannel marketing, consistency or commonality in online and offline trust and in transfer of trust across the multiple touch points or channels (e.g. Web, phone, mail, kiosk, email, physical store) is becoming important. Each touch point may have its own unique elements of trust in addition to common elements of trust across the different touch points. Consider, for example, a bank customer interacting with an automated teller machine (ATM), one of the multiple touch points available to customers. In addition to the elements of trust common to all the touch 
points, a concern that is specific to the ATM is whether the ATM card will be returned by the machine. Typically, customers expect all touch points or channels to provide accurate and unbiased information, easy navigation (Web site and store layout), and consistent touch (colors, people, personas). Inconsistency among different channels could be a trustbuster. For instance, if trust on the Web site alone is high, but if the firm is perceived as having pushy sales people or hard-selling telemarketers, or if the channels do not offer the same information that generate or maintain trust, then online trust across the channels is inconsistent. The issue of transfer of trust across channels is rooted in the general concept of transitivity of trust across three or more channels. Therefore, the issue of linkage between online and offline trust is important to study.

\section{A stakeholder perspective of online trust}

Online trust and its relationship with its antecedents and consequences can be viewed from the perspectives of multiple stakeholders such as customers, employees, suppliers, distributors, partners, stockholders, and regulators (see Fig. 1). Stakeholder theory has attracted considerable attention in recent years (Donaldson and Preston, 1995). The theory focuses on managerial decision-making in the context of the processes and outcomes of a company's relationships with multiple stakeholder groups that affect and are affected by its decisions (Jones and Wicks, 1999). Relationship with each stakeholder group has intrinsic value and no set of interests is assumed to dominate the others.

Different stakeholders may have different views and requirements of online trust (see Table 1 for a summary of the orientation of different stakeholders toward online trust). From a customer's viewpoint, a company's Web site may need to be trustworthy for doing business and getting reliable customer information and service. From a supplier's perspective, the key requirements may be efficiency, preservation of confidentiality and preferential access to buyer information. From a distributor's perspective, the central online trust requirement could be channel complentarity. From a stockholder's point of

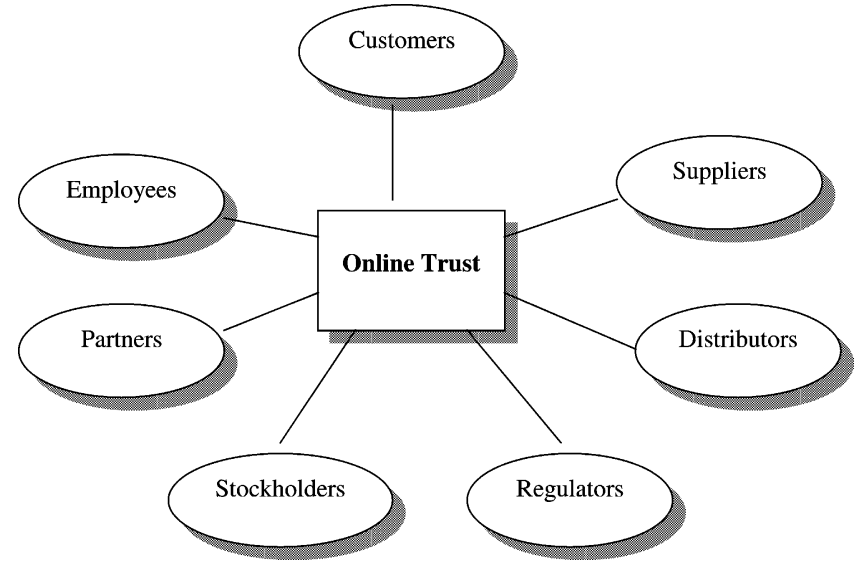

Fig. 1. Stakeholders involved with online trust. 
Table 1

Stakeholder orientation of online trust

\begin{tabular}{|c|c|}
\hline Stakeholder & Orientation \\
\hline Customer & $\begin{array}{l}\text { How trustworthy is the firm's Web site for doing business, making purchases, getting customer } \\
\text { information, and getting service? How safe is the transaction and my personal/company } \\
\text { information that I give on the Web site? How comfortable do I feel in my online experiences } \\
\text { with the firm? }\end{array}$ \\
\hline Employee & $\begin{array}{l}\text { How accurate and reliable is the information to employees? How transparent are the company } \\
\text { policies? How competent is the service for employees? How receptive is the company to } \\
\text { employee feedback and interactions on the Web? }\end{array}$ \\
\hline Supplier & $\begin{array}{l}\text { How competent is the company in its Web-site interactions with suppliers? How confidential is } \\
\text { the information sharing? Do I have preferential access to important information about the } \\
\text { buyer? Is the firm trustworthy for online collaboration? Is the online information reliable? Is } \\
\text { the online information consistent with offline information? }\end{array}$ \\
\hline Distributor & $\begin{array}{l}\text { How competent is the company in its Web-site interactions with distributors? How } \\
\text { confidential is the information sharing? Is the firm trustworthy for online collaboration? Is the } \\
\text { online information reliable? Is the online information consistent with offline information? Is } \\
\text { the Web site a channel complementor? Are lead referrals accurate, current, and screened for } \\
\text { potential? }\end{array}$ \\
\hline Partner & $\begin{array}{l}\text { Can I expect the firm's Web site to promote my offering? Is my trust enhanced online as a } \\
\text { result of the partnership? Do I have preferential access to important information about my } \\
\text { partner? Can I depend on the company's Web site to accurately present my information? }\end{array}$ \\
\hline Stockholder & $\begin{array}{l}\text { How accurate and timely is the information on company's activities and performance? How } \\
\text { transparent is the company's strategy and performance on the Web? How complete and } \\
\text { unbiased is the information? Can I identify vulnerabilities as well and successes? }\end{array}$ \\
\hline Regulator & $\begin{array}{l}\text { Is there adequate information on compliance of regulations on the Web site? Is the company } \\
\text { transparent online in its compliance of relevant laws? Does the Web site conform } \\
\text { to privacy regulations? Do the company and its Web site securely protect financial and } \\
\text { credit card information? Do the company and its Web site have a reliable and fair mechanism } \\
\text { for addressing failures or violations of regulations? }\end{array}$ \\
\hline
\end{tabular}

view, trust on a firm's Web site might be related to the accuracy and timeliness of information on firm strategy and performance. From a regulator's standpoint, a trustworthy Web site may well be one that offers transparency with respect to its compliance of regulations. In addition, many of these perspectives may depend on offline relationships with the stakeholders. For example, a channel member's perception of online trust for a firm may be contingent on the balance of power between the firm and the channel member.

A key issue in stakeholder theory is economic efficiency (Freeman, 1994). Economic efficiency in this context refers to the ability of the firm to manage the interests of its multiple stakeholders. In the context of online trust, because of the divergence of interests of some of the stakeholders, the different stakeholder perspectives cannot be easily aligned for economic efficiency of the firm. Building and maintaining Web sites and electronic networks with high levels of trust with different stakeholders may call for a delicate balancing of the interests of these stakeholders.

Some elements of online trust may be compatible across stakeholders, while others may not be compatible. For example, open and unbiased information may be a common need 
for all stakeholders. An image of a company's business ethics also cuts across the different stakeholders. Some needs, however, may be conflicting. For example, too much transparency in prices to customers that may promote trust among customers may be undesirable for distributors who may view that as an enabler of potential channel conflict.

An issue related to the stakeholder perspective of online trust is the role of alliances and partnerships in online trust (partner's view of online trust). Online trust can be impacted by online partnerships just as offline trust can be. Conceptually, online trust for one party may increase, decrease or remain the same after a strategic alliance with another party. Consider, for example, the online alliance between AOL and Autoweb, an online automobile selection service. One view is that because AOL is the leading online service provider in the US, it enjoys a high degree of trust among online service users and visitors to the AOL Web site. By being the preferred autoselection service on AOL, Autoweb stands to gain a higher level of trust from its stakeholders than when it is not linked to AOL. Autoweb is the second largest online autoselection service (measured in terms of automobiles bought through online services) and thus enjoys a high degree of trust. It is likely that AOL's trust with Autoweb online alliance is somewhat higher than it is without the alliance. Another view is that AOL may be perceived as biased because it lists Autoweb as the sole source of automobile information, thereby losing some trust among its customers. It could therefore dilute its trust in the long run.

Thus, online trust for both AOL and Autoweb may increase or decrease as a result of the alliance. The extent of changes in online trust for AOL and Autoweb and in general, the direction and magnitude of changes in online trust as a result of online alliances, are an empirical question. These changes may also impact the trust that each partner has in the other partner.

Research on alliances and trust suggests how online trust may be managed in partnership contexts. Gulati (1995) examines how repeated relations in alliances lead to trust in the offline context. Stewart (2003) develops and tests a cognitive model of the trust transfer process online, arguing that trust is transferred across hypertext links based on the perceived interaction and similarity of the linked organizations and that institution-based trust is transferred from the traditional shopping channel to a Web-based organization based on evidence that the Web-based organization has a physical store. Hypertext link from one Web site to another had a positive influence on trusting beliefs regarding the linked sites. Associating with the physical shopping channel by showing a picture of a building on a Web site also increased the extent to which subjects reported intention to buy from the site.

\section{A broad conceptual framework of online trust}

We develop a broad conceptual framework of trust, its antecedents and its consequences based on past research. Because our focus is online trust and its business implications for managers, we review the relevant trust studies in the management and marketing, information systems, and e-business literatures, although many of them relate to offline trust. We recognize that trust has been extensively studied in other areas such as accounting and computer science that have focused on trustworthy information and 
systems, respectively. In reviewing these studies, we focus on the importance of trust, the definition or elements of trust, its antecedents and its consequences. We also discuss the implications for multiple stakeholders where appropriate.

\subsection{Management literature}

In the management literature, trust is considered important because it is a good predictor of satisfaction (Driscoll, 1978), it reduces uncertainty (Mayer et al., 1995), it is a form of organization control (Creed and Miles, 1996), and it is a transaction cost reduction mechanism (Wicks et al., 1999). Trust is also important in particularistic organizations in which employees are rewarded for who they are rather than based on impersonal judgments about their performance (Pearce et al., 2000). Trust is important, in particular, in the online environment because implementation of a computer-mediated technology such as the Internet can impact trust in organizations (Zuboff, 1982) and trust is relevant in virtual organizations (Handy, 1995).

Trust has been defined in various terms ranging from 'the willingness to be vulnerable to the actions of another party' (Mayer et al., 1995) to 'the probability one attaches to cooperative behavior by other parties' (Hwang and Burgers, 1997) to an individual's beliefs about the extent to which a target is likely to behave in a way that is 'benevolent, competent, honest, [and] predictable in a situation' (McKnight et al., 1998).

Much of the work on trust in the management and organization literature relates to trust within and across organizations (Jarvenpaa and Leidner, 1999; Pearce et al., 2000; Zaheer et al., 1998). Although they apply to trust from the perspectives of employees and organizational entities, they are relevant for customer perspective of online trust as well because trust in organizations and in individuals are correlated (Zaheer et al., 1998).

Among the several antecedents and consequences of trust in organizations that have been proposed, a few of them may be relevant to online trust. Global virtual working context impacts trust within organizations. Creating and maintaining trust in a global virtual team whose members transcend time, space, and culture is challenging and any trust that results may be fragile and temporal (Jarvenpaa and Leidner, 1999). Zaheer et al. (1998) show that both interorganizational and interpersonal trust influence firm performance. Trust has a positive effect on uncertainty reduction and organizational results.

These studies may have important implications for online trust. Benevolence, competence and predictability could be important elements of online trust as well. In the online context, the definitions in the literature are consistent with stakeholder expectations of the predictability of the firm in offering expected service on the Internet, and the potential consequences of trust on satisfaction and uncertainty reduction are also equally relevant.

\subsection{Marketing literature}

The marketing literature has focused on trust primarily in the relationship marketing context because trust has been perceived to be important to a firm's relationship marketing strategy (Doney and Cannon, 1997; Dwyer et al., 1987; Ganesan, 1994; Kumar, 1996; 
Morgan and Hunt, 1994). A frequently used definition is 'willingness to rely on an exchange partner in whom one has confidence' (Moorman et al., 1993). Trust can be viewed as both a belief in the trustworthiness of a partner and a behavioral intention to rely on a partner in a situation of vulnerability. Credibility and benevolence are the underlying dimensions of trust (Doney and Cannon, 1997; Ganesan, 1994; Ganesan and Hess, 1997). Credibility refers to the buyer's belief in the seller's expertise to do the job effectively, while benevolence is based on the buyer's belief in the positive intention of the seller (Ganesan, 1994). Trust is multidimensional involving two distinct cognitions relating to provider competence and benevolence (Singh and Sirdeshmukh, 2000).

The antecedents of a buyer's trust in a seller include the seller's reputation for reliable, consistent and fair behavior (Ganesan, 1994), relationship-specific investments by the seller, the seller's size (Doney and Cannon, 1997), the buyer's experience with the seller (Anderson and Weitz, 1989; Ganesan, 1994), and the incidence of opportunistic behavior by the seller (Morgan and Hunt, 1994). Brands are also important to the development of trust in Web-based relationship marketing (Davis et al., 1999). Brand is the trust mark that is the cue for all the past trust generating activity and in the absence of human touch, it can be a symbol of quality and assurance that is capable of building trust.

The consequences of trust are long-term exchange relationship (Ganesan, 1994) and cooperation (Morgan and Hunt, 1994). Although these positive outcomes exist, trust in a seller firm or salesperson may not affect choice of the seller if factors such as delivery performance, price and product performance are appropriately accounted for (Doney and Cannon, 1997). It is, however, possible that price and performance may drive both the buyer's trust in and its choice of the seller. Singh and Sirdeshmukh (2000) show that trust mediates the relationship between agency mechanisms and satisfaction and between satisfaction and loyalty.

In a meta analysis of studies on trust in marketing relationships, Geyskens et al. (1998) show that environmental uncertainty, own dependence, partner's coercive power use, communication and economic outcomes are the primary antecedents of trust, while satisfaction and long-term orientation are the consequences of trust.

When applied to online trust, these studies have important implications. First, credibility and benevolence could be two important underlying dimensions of online trust as well because they relate to issues that are common to both online and offline contexts. Second, a firm's reputation, size and a user's past experience with the firm and its Web site, user's dependence on the firm, and communication between the firm and the user are potential antecedents in the online context. Finally, satisfaction, commitment, and longterm interactions with the Web site could be some of the consequences of online trust. Online trust, however, is likely to have other dimensions, antecedents and consequences as well.

\subsection{Information systems and e-business literature}

The information systems and e-business perspective on trust has grown over time. Much of this literature focuses on the perspective of customers. Thus, little is known about the stakeholder orientation of online trust in this literature. Trust is important in the adoption of new technologies including the Web (Fukuyama, 1995). Because of the high 
uncertainty associated with e-commerce, companies can behave in an opportunistic manner on the Internet, making their behavior unpredictable. Thus, online trust or trust on the Internet is assuming a lot of importance. A summary of selected studies on online trust is shown in Table 2.

There has been limited research on the underlying dimensions of trust. Trust spans several aspects including browsing, buying, after sales and security according the assessment criteria of Casetrust (University of Hong Kong, 2000). From a privacy standpoint, trust can be viewed as the customer's expectation that the online business will treat the customer's information fairly. Sultan et al. (2002), in a large scale empirical analysis of 6700 responses on 25 Web sites, uncovered three underlying dimensions of trust, namely, believability/reliability, visual feel/comfort and quality of the company.

Several studies have examined antecedents of online trust. Trust is driven by past experiences, long-term orientation, positive trusting stance, and feeling of control (Jarvenpaa et al., 1999). The quantity, quality and timeliness of information and virtual personal advisors can enhance trust (Urban et al., 2000). Dayal et al. (1999) propose a trust pyramid in which state-of-art security, merchant legitimacy, and fulfillment are the core drivers of online trust while customer control, tone and ambience and consumer collaboration are the differentiating drivers. Other potential drivers of online trust include site longevity, selection of items, online community, links to and from other sites, search engine on the site, and privacy (Smith et al., 2000).

Hoffman et al. (1999) focus on security and privacy as the key drivers of online trust. They argue that environmental control or consumer's ability to control the actions of a Web vendor directly affects consumer perception of security and privacy online. Jarvenpaa et al. (2000) found that perceived size and perceived reputation determined trust in an electronic store. Sultan et al. (2002) found that customer perceptions of trust are determined by Web site and consumer characteristics. Nine Web-site factors, namely, navigation, advice, no errors, fulfillment, community, privacy/security, trust seals, brand and presentation drive trust. Four consumer factors, namely, Internet savvy, past site experience, Internet shopping experience, and entertainment/chat or Web use also affects trust.

Lee and Turban (2001) propose that consumer trust in Internet shopping is driven by trustworthiness of Internet merchant, trustworthiness of Internet shopping medium and contextual factors and that individual trust propensity moderated each of the relationships between the antecedents of trust and trust. Trustworthiness is driven by seals of approval (logos of security firms), branding, fulfillment, navigation, presentation and technology (Cheskin/Sapient Report, 1999). These six building blocks can be further divided into 28 specific ways to establish trustworthiness.

Fogg et al. (2001) conducted an empirical study of people's perception of Web-site credibility on 1400 students in the US and Europe who evaluated 51 different Web-site elements relating to trust. They found that real-world feel, ease of use, expertise, trustworthiness, and tailoring to be the most important factors affecting Web credibility, in that order. These factors were defined and the scale items were designed a priori and were not empirically derived.

Yoon (2002) studied trust in the context of online purchase decision-making through simulation and surveys. He concluded that Web-site trust is determined by company 
Table 2

Review of selected studies on online trust

\begin{tabular}{lll}
\hline Study & $\begin{array}{l}\text { Stakeholder focus; } \\
\text { topic of analysis }\end{array}$ & Results \\
\end{tabular}

Dayal et al. (1999) Customer; elements of online trust

Jarvenpaa et al. (1999)

Cheskin/Sapient

Report (1999)

Hoffman et al.

Smith et al. (2000) Customer; indicators of online trust

Urban et al. (2000) Customer; how to improve online trust

Jarvenpaa et al. (2000)

Schneiderman (2000)

Palmer et al. (2000)

Lee and Turban (2001)

Pan et al. (2001)

Mathew et al. (2001) Customer; how to enhance online trust

Fogg et al. (2001)

Yoon (2002)
Customer; how to improve online trust

Customer, intermediary; how to improve online trust

Customer; antecedents of trust

Customer; drivers of online price dispersion

State-of-art security, merchant legitimacy, and fulfillment are the core elements of online trust while customer control, tone and ambience and consumer collaboration are the differentiating elements

Trust different in early versus late stage of e-commerce. Trust is driven by long-term orientation, positive stance, and feeling of control

Six building blocks of trustworthiness: seals of approval, branding, fulfillment, navigation, presentation and technology Environmental control or consumer's ability to control the actions of a Web vendor directly affects perception of security and privacy, key drivers of online trust

Site longevity, selection of items, online community, links to and from other sites, search engine on the site, and privacy are indicators of online trust

Provide virtual advisor, unbiased information, keep promises, and offer reliable fulfillment

Perceived size and perceived reputation determined trust in an electronic store, which affected the attitude, risk perception and which, in turn, influenced the willingness to buy in an electronic store. Communication of policies of customer satisfaction, returns and refunds improve trust Past performance, references from past and current users, third-party certifications, and easy to locate, read and enforce policies involving privacy and security improve online trust

Privacy statements and third-party involvement can improve trust

Trustworthiness of Internet merchant, trustworthiness of Internet shopping medium and contextual factors. Individual trust propensity moderated each of the relationships between the antecedents of trust and trust

Trust is positively associated with prices only in one category, the consumer electronics category. It is not significant in five categories, but negative in two categories, DVD and desktop computers

Credit card loss assurance, product warranty and merchandise return policies, availability of escrow service, ability to schedule human customer service, and availability of user friendly interfaces

Real-world feel, ease of use, expertise, trustworthiness, and tailoring are the most important factors affecting Web credibility, in that order

Company awareness and reputation and consumer familiarity and prior satisfaction with e-commerce determine Web-site trust, which in turn, influences purchase intention. Web-site trust is correlated with Web-site awareness and Web-site satisfaction 
Table 2 (continued)

\begin{tabular}{|c|c|c|}
\hline Study & $\begin{array}{l}\text { Stakeholder focus; } \\
\text { topic of analysis }\end{array}$ & Results \\
\hline Sultan et al. (2002) & $\begin{array}{l}\text { Customer; determinants } \\
\text { and consequences of } \\
\text { online trust }\end{array}$ & $\begin{array}{l}\text { Web site and consumer characteristics drive trust, which } \\
\text { drives customer Web behavior. Trust mediates the effects of } \\
\text { Web site and consumer characteristics on Web behavior }\end{array}$ \\
\hline Shankar et al. (2002) & $\begin{array}{l}\text { Customer, partner; role } \\
\text { of trust in online custo- } \\
\text { mer support }\end{array}$ & $\begin{array}{l}\text { Trust moderates the relationships between perceived infor- } \\
\text { mation availability and problem resolution and between } \\
\text { problem resolution and customer satisfaction. The positive } \\
\text { effects of perceived information availability and problem } \\
\text { resolution on customer satisfaction are significantly enhanced } \\
\text { by trust with the online provider }\end{array}$ \\
\hline Pan et al. (2002b) & $\begin{array}{l}\text { Customer; comparison } \\
\text { of Web-site traffic and } \\
\text { price across different } \\
\text { types of e-tailers }\end{array}$ & $\begin{array}{l}\text { Trust increases site traffic in two categories (gifts and flowers } \\
\text { and computer hardware), but is not significant in six } \\
\text { categories. Trust has insignificant effect on price }\end{array}$ \\
\hline
\end{tabular}

awareness and reputation and consumer familiarity with e-commerce and prior satisfaction with e-commerce.

Different studies have shown different consequences of online trust. Sultan et al. (2002) show that online trust significantly affects customer intent to act, which could include purchase and loyalty. Their key finding is that trust mediates the impact of consumer and Web-site factors on intent to act. Trust affected the attitude, risk perception and which, in turn, influenced the willingness to buy in an electronic store (Jarvenpaa et al., 2000). Website trust influences purchase intention (Yoon, 2002).

A few studies have examined online price dispersion and the effect of trust on prices and price dispersion on the Internet (Pan, Ratchford and Shankar, 2001; Pan, Ratchford and Shankar, 2002; Pan, Shankar and Ratchford, 2002; Ratchford, Pan and Shankar, 2003). In a study of price competition between pure play and bricks-and-clicks e-tailers across eight product categories, Pan et al. (2002b) found that online trust had a positive impact on Web-site traffic in two categories, gifts and flowers and computer hardware, but no significant effects in the other six categories, namely, apparel, health and beauty, home and garden, sports and outdoor equipment, electronics, and office supply. The effects of trust on prices were insignificant in all the eight categories they studied. In a study of price levels and price dispersion across another eight categories, Pan et al. (2001) found that trust is positively associated with prices only in one category, the consumer electronics category. It was not significant in five categories, but negative in two categories, DVD and desktop computers. In all these studies, the operationalization of trust was the number of trust seals that an e-tailer had on its Web site. Therefore, only the security and privacy aspects of trust were addressed.

A few studies have examined online trust in customer support and international contexts. Shankar et al. (2002) study the role of trust in the relationships among information availability, problem resolution and customer satisfaction in the online support context. They show that trust moderates the relationships between perceived 
information availability and problem resolution and between problem resolution and customer satisfaction. The positive effects of perceived information availability and problem resolution on customer satisfaction are significantly enhanced by trust with the online provider.

Cheskin Research (2000) studied differences in online trust across international contexts. US and Brazilian consumers tend to be more cynical about the ability of governments and Web sites to control identity and other forms of risk than Spanishspeaking Latin Americans. At the same time, Latin Americans and Brazilians gain more from the presence of credit card symbols on sites than do US residents. The study found that Yahoo! is the most trusted Web site in the US and ranks closely with Hotmail/MSN in Latin America. In Brazil, however, the top two most trusted Web sites were banks, possibly due to the fact that they often function as ISPs to account holders.

A problem that runs throughout most of the studies on online trust is the lack of clear distinctions between the underlying dimensions and antecedents of online trust. Elements and determinants of online trust are used interchangeably in many studies. Another important limitation is the lack of focus on stakeholders other than customers.

Nevertheless, based on past research and careful conceptual distinctions among the different constructs, a broad conceptual framework of online trust emerges as shown in Fig. 2. The antecedent factors could be classified into three broad groups: (1) Web-site characteristics, (2) user characteristics, and (3) other factors. The other factors include such factors as the online medium and variables involving a combination of Web site and user characteristics. The consequences could be broadly grouped into three categories: (1) intent to act, (2) stakeholder satisfaction and loyalty, and (3) firm performance. Although the framework is not specific to any particular stakeholder, we must recognize that the antecedents and consequences are primarily based on customer perspective because prior research has been centered on customers.

\section{Implications for how companies can build and maintain online trust}

Stakeholder analysis and the antecedents of trust from the conceptual model offer important implications for how companies can build and maintain online trust. We discuss the implications from stakeholder analysis first and from the conceptual model next.

Companies should undertake initiatives to enhance of online trust based on the perspectives of multiple stakeholders. One way to build and maintain online trust from a stakeholder orientation is to use the following approach. First, the organization should clearly understand and articulate the key requirements of online trust from the different stakeholders (Table 1 could be used as a starting point). Second, the firm should identify the common or consistent requirements across the stakeholders, while simultaneously listing the conflicting needs. Third, it should prioritize stakeholder needs based on key criteria that could include relationship to firm performance, future growth, competitive necessity and other factors relating to organization objectives. Finally, it should choose direction of trust development in line with the prioritized needs. The prioritization will be a useful guide in particular when the trust needs of two or more stakeholders are in conflict. 


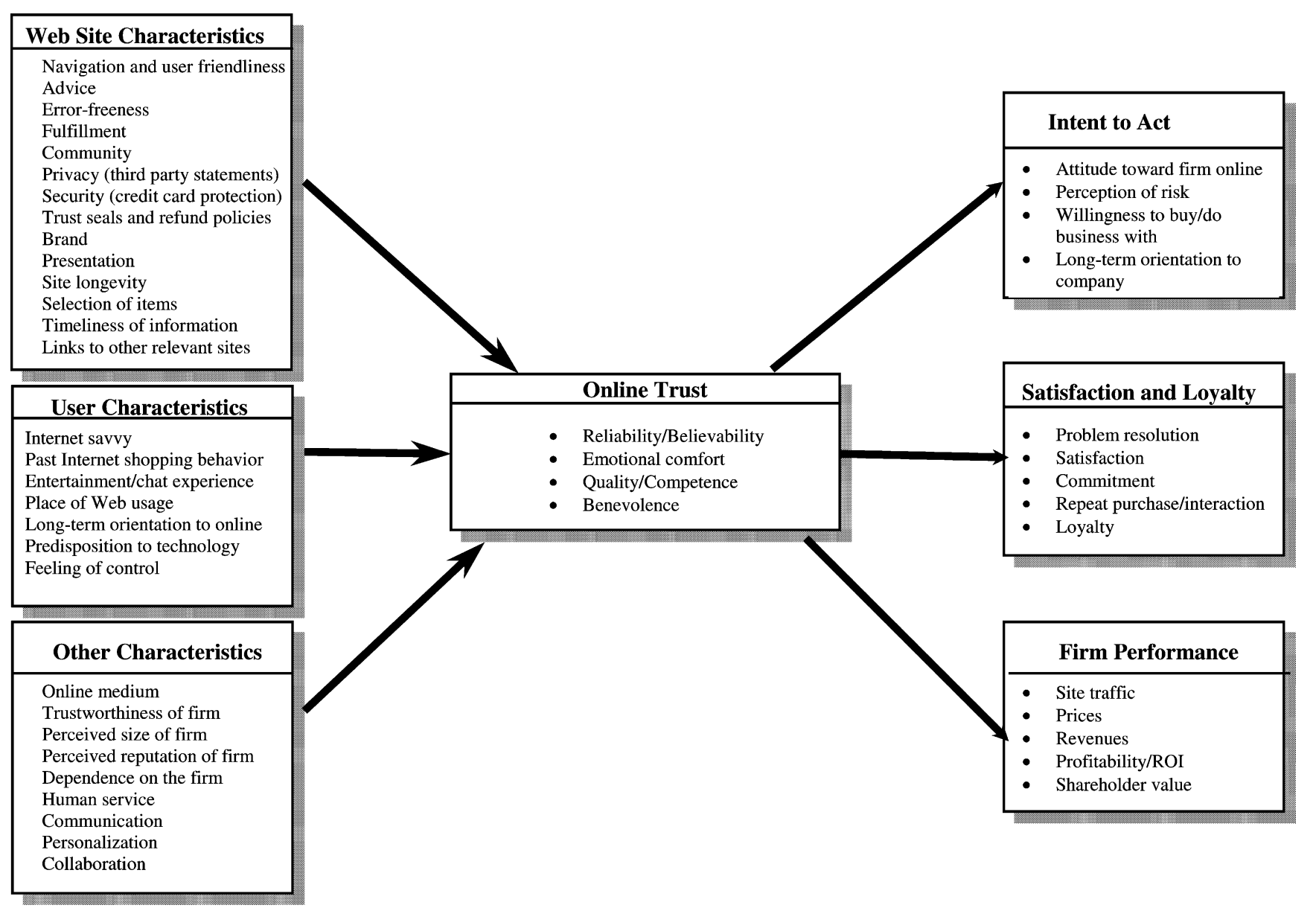


From the conceptual model, although trust can be enhanced online, it can be diminished or lost due to problems with its drivers such as inferior product quality, poor content of the Web site, complex or unintuitive navigation, technology failure(s), inferior customer service, poor response time, and order fulfillment mistakes. Furthermore, the extent of gain and loss in online trust could be asymmetric. Prospect theory (Kahneman and Tversky, 1979) suggests that losses loom larger than gains for individuals. Put differently, the value of a loss of trust is larger than that of a value of a gain in trust. Thus, it is difficult to earn, but is easy to lose online trust for firms. While the process of building online trust can be gradual, the process of losing trust can be steep. Trust can be built incrementally through reinforcing encounters with the firm and its Web site. However, with one major failure or setback, this trust could be lost altogether. Even if online trust is strong, it could be lost if offline experience is untrustworthy. Thus, a multichannel strategy to building trust is critical.

Based on prior research, online trust can be enhanced in several ways. It can be improved by increasing (decreasing) the levels of positive (negative) drivers of online trust where possible. In addition, many studies suggest specific initiatives. For example, Urban et al. (2000) recommend the following ways to building trust online: maximize cues that build Web-site trust, use virtual-advisor technology to gain customer confidence and belief, provide unbiased and complete information, include information on competitive products and keep promises. Dayal et al. (1999) suggest that user driven-personalization may be key to enhancing trust at higher levels. The best companies let users set the pace of personalization and of contact from marketers. Trust can be improved by quoting policies of customer satisfaction, returns and refunds (Jarvenpaa et al., 2000). Online trust can be enhanced by giving consumers the opportunity to be anonymous or pseudonymous when engaging in information exchanges and online transactions (Hoffman et al., 1999). In the long-run, online trust can be built mainly by having a balance of power that signifies a cooperative interaction between an online business and its customers.

Companies can improve online trust by disclosing patterns of past performance, provide references from past and current users, get third-party certifications, and make it easy to locate, read and enforce policies involving privacy and security (Schneiderman, 2000). Mathew et al. (2001) suggest that trust can be enhanced by credit card loss assurance, product warranty and merchandise return policies, availability of escrow service, ability to schedule human customer service, and availability of user friendly interfaces. Privacy statements and third-party involvement can improve trust (Palmer et al., 2000). Because different organizations such as retailer, shipping courier, and bank are involved in an online transaction, online trust may increase if these organizations work well together.

\section{Future research directions}

There are several unexplored areas of online trust that present fertile opportunities for future research relating to online trust. Some of these can be investigated empirically with the availability of data that may not be very difficult to collect. Others, however, can be 
challenging from the standpoint of data collection and availability. Future research could address the following issues in depth.

\subsection{Relationship with e-business strategy}

Although online trust is related to a firm's e-business strategy conceptually, empirical evidence on this relationship is sparse. It would be useful to deeply examine this relationship. While there is a notion that a minimum level of trust is needed for a sound e-business strategy, there is also the view that e-business strategy is optimal when trust levels are at a maximum. The degree of trust dependence in e-business strategy may be driven by customer power and competitive intermediaries' influence among other factors. Investigation of these issues will help better understand the role of online trust in firm strategy and could lead to better insights on the link between trust and strategy in general.

\subsection{Relationship with offline trust}

What is the interrelationship between online and offline trust? With the trend toward multichannel strategies or bricks-and-clicks approaches by firms, managers need a better understanding of how their online and offline strategies affect online and offline trust and how to improve overall trust. How can firms have a cohesive strategy for building and maintaining trust across all channels? How can trust be effectively transferred from one channel to the other? Answers to these questions could help form a conceptual model of multichannel trust.

\subsection{Stakeholder perspective}

There has not been much empirical research on online trust from the standpoints of stakeholders other than the customers. For example, is a supplier's perception of a trust different a distributor's perception of trust? If so, what implications does it have for the design of Web sites and electronic networks? What are the likely consequences on firm performance? How can these perspectives be aligned and managed for better firm performance? How should conflicting online trust needs among stakeholders be traded-off and balanced? Can the stakeholder approach for improving online trust proposed in this paper be validated through empirical analysis? Research into these questions can potentially lead to a generalizable stakeholder theory of online trust.

\subsection{Cross-cultural differences}

The topic of cross-cultural and international differences in trust perceptions is another ripe area for future research. Because the Web eliminates some physical barriers, some might believe that there should not be differences in online trust across the world. The Web, however, does not still eliminate psychological barriers. Therefore, firms will have to be culturally sensitive in building online trust across cultures. On could even argue that because of the underestimation of the importance of cultural sensitivities online, crosscultural differences may be more important in the online context than in the offline context. 
Important research questions in cross-cultural differences in online trust include the following. Are the antecedents of online trust different or do they have different impacts on trust in high versus low context cultures? Are the consequences of online trust different in different cultural contexts? Does the availability of Web sites, extranets and Intranet in local language enhance trust? How can companies more carefully tailor their Web-site efforts to the specific perspectives of each region or culture? These issues could be addressed, extending Cheskin Research (2000) and the cross-cultural validation work of Jarvenpaa et al. (1999) in the context of an online retail store. More research in this issue can bring about a theory of online trust in global environments.

\subsection{Role of trust in online alliances}

How does customer trust in two parties affect their alliances or partnerships? Can a company with low online customer trust increase its online trust by partnering with another company with a high level of customer trust? Does a firm with high online trust dilute its trust by partnering with a company with low trust? Is there a synergistic effect on the online trust of two companies with high levels of trust? Can online trust be enhanced through co-marketing and co-branding alliances? These issues could be addressed in greater depth, extending the work by Stewart (2003).

\subsection{Online trust and branding}

Trust is one of the most important factors associated with branding (Cheskin Research, 2000). Although brand is one of the determinants of online trust (Cheskin/Sapient Report, 1999; Sultan et al., 2002), often, the impacts of brand and trust on their consequences such as purchase intention and sales are blurred. Brand equity is driven by preference and satisfaction with product or service and advertising. Alternatively, does enhancement of online trust improve brand equity? Future research could focus on the interrelationship between branding and online trust and on the ways to tease the impacts of these constructs on consequent constructs. Additional insights into these issues could potentially lead to a model of branding and trust that transcend media and channels.

\subsection{Online trust and quality}

What is the relationship between quality and trust? How much is trust based on product performance versus based on trust cues on the Web site? How does product use fit into the process of building trust? Can increase in product quality enhance online trust? Are quality enhancements compatible with trust reinforcements over time? The complex interrelationship between quality and trust is worth further exploration in future studies.

\subsection{Online trust and CRM}

How does customer relationship management (CRM) fit with trust? Is online trust positively associated with returns on CRM initiatives? Because CRM is focused on targeted customer segments or customers, are communication and interaction with these 
segments or customers related to online trust? How can a deeper understanding of online trust help better manage customer relationships? Answers to these questions should lead to a managerially insightful relationship theory built on trust.

\section{Conclusion}

Online trust is important to a firm's e-business strategy. Although online trust shares many common elements with offline trust, it is different from offline trust in that technology rather than just the organizational entity is an object of trust. Online trust can be approached from a stakeholder perspective that takes into account the viewpoints of multiple stakeholders such as customers, employees, suppliers, distributors, partners, stockholders, and regulators. It is a multidimensional construct whose underlying dimensions include reliability/credibility, emotional comfort, quality and benevolence. The determinants of online trust include Web-site characteristics, customer characteristics, and other factors. The consequences include intention to act, stakeholder satisfaction, loyalty, traffic, price, revenues, profitability, and shareholder value. A company should clearly understand the online trust related needs of different stakeholders, address the common needs, prioritize any conflicting needs, and go about enhancing online trust based on the dominant drivers of online trust in its business context. Online trust is a relatively under explored topic that offers several promising avenues for future research including the roles of multiple stakeholders, the impact of strategic alliances, and cross-cultural differences in perceptions of trust.

\section{Acknowledgements}

We thank Sirkka Jarvenppa, V. Sambamurthy and Michele Costabile for insightful comments. Please address all correspondence to Venkatesh Shankar.

\section{References}

Anderson, E., Weitz, B., 1989. Determinants of continuity in conventional industrial channel dyads. Marketing Science 8, 310-323.

BusinessWeek, 2001. It's All About Trust, December 3.

Cheskin Research and Studio Archetype/Sapient Report, 1999. Ecommerce Trust Study. http:// www.sapient.com/cheskin.

Cheskin Research, 2000. Trust in the Wired Americas, July. http://www.cheskin.com/think/studies/ trust2.html.

Creed, W.E.D., Miles, R.E., 1996. Trust in organizations: a conceptual framework linking organizational forms, managerial philosophies, and the opportunity costs of controls. In: Kramer, R.M., Tyler, T.R. (Eds.), Trust in Organizations: Frontiers of Theory and Research, Sage Publications, London, pp. 16-38. 
Davis, R., Buchanan-Oliver, M., Brodie, R., 1999. Relationship marketing in electronic commerce environments. Journal of Information Technology 14, 319-331.

Dayal, S., Landesberg, H., Zeisser, M., 1999. How to build trust online. Marketing Management Fall, 64-69.

Donaldson, T., Preston, L., 1995. The stakeholder theory of the corporation: concepts, evidence and implications. Academy of Management Review 20, 65-91.

Doney, P.M., Canon, J.P., 1997. An examination of the nature of trust in buyer-seller relationships. Journal of Marketing 61, 35-51.

Driscoll, J.W., 1978. Trust and participation in organizational decision making as predictors of satisfaction. Academy of Management Journal 21 (1), 44-56.

Dwyer, R.F., Schurr, P.H., Oh, S., 1987. Developing buyer-seller relationships. Journal of Marketing 51 (April), 22-27.

Ernst and Young Report, 1999. The Second Annual Ernst \& Young Internet Shopping Study. http:// www.ey.com/global/gcr.nsf/US/1999_Internet_Shopping Motivator_-_Retail_\&_Consumer_Proudcts_-_Ersnt_\&_Young_LLP.

Fogg, B.J., Marshall, J., Laraki, O., Osipovich, A., Varma, C., Fang, N., Paul, J., Rangnekar, A., Shon, J., Swani, P., Treinen, M., 2001. What makes Web sites credible? A report on a large quantitative study. ACM SIGCHI 3 (1), 61-67.

Forrester Report, 2000. http://www.forrester.com/Research/CoverageIndex/0,5909,00.html.

Freeman, R.E., 1994. The politics of stakeholder theory: some future directions. Business Ethics Quarterly 4, 409-422.

Fukuyama, F., 1995. Trust: The Social Virtues and the Creation of Prosperity, The Free Press, New York, NY.

Ganesan, S., 1994. Determinants of long-term orientation in buyer-seller relationships. Journal of Marketing 58, 1-19.

Ganesan, S., Hess, R., 1997. Dimensions and levels of trust: implications for commitment to a relationship. Marketing Letters 8 (4), 439-448.

Geyskens, I., Steenkamp, J.-B.E.M., Kumar, N., 1998. Generalizations about trust in marketing channel relationship using meta-analysis. International Journal of Research in Marketing 15, 223-248.

Gulati, R., 1995. Does familiarity breed trust? The implications of repeated ties for contractual choice in alliances. Academy of Management Journal 38, 85-112.

Hoffman, D.L., Novak, T.P., Peralta, M., 1999. Building consumer trust online. Communications of the ACM 42 (4), 80-85.

Hwang, P., Burgers, W., 1997. Properties of trust: an analytical view. Organizational Behavior and Human Decision Processes 69 (1), 67-73.

Jarvenpaa, S.L., Leidner, D.E., 1999. Communication and trust in global virtual teams. Organization Science 10 (6), 791-815.

Jarvenpaa, S.L., Tractinsky, J., Saarinen, L., 1999. Consumer trust in an internet store: a crosscultural validation. Journal of Computer Mediated Communication 5 (2) http://www.asusc.org/ $\mathrm{jcmc} / \mathrm{vol} 5 /$ issue 2 .

Jarvenpaa, S.L., Tractinsky, J., Vitale, M., 2000. Consumer trust in an Internet store. Information Technology and Management 1 (1/2), 45-71.

Jones, T.M., Wicks, A.C., 1999. Convergent stakeholder theory. Academy of Management Review 24 (2), 206-221.

Jupiter Consumer Survey Report: Retail, 2001, http://commerce.jmm.com/jupdirect.asp?mode = display\&itemid $=1909$.

Handy, C., 1995. Trust and virtual organization. Harvard Business Review 73 (3), 40-50.MayJune. 
Kahneman, D., Tversky, A., 1979. Prospect theory: an analysis of decisions under risk. Econometrica 47 (March), 263-291.

Kumar, N., 1996. The power of trust in manufacturer-retailer relationships. Harvard Business Review 74, 92-106.November-December.

Lee, M.K.O., Turban, E., 2001. A trust model for consumer internet shopping. International Journal of Electronic Commerce 6 (1), 75-91.

Luhmann, N., 1979. Trust and Power, Wiley, London.

Marcella, A.J., 1999. Establishing Trust in Vertical Markets, The Institute of Internal Auditors, Altamonte Springs, FL.

Mayer, R.C., Davis, J.H., Schoorman, F.D., 1995. An integrative model of organizational trust. Academy of Management Review 20, 709-734.

McKnight, D.H., Cummings, L.L., Chervany, N.L., 1998. Initial trust formation in new organizational relationships. Academy of Management Review 23, 473-490.

Moorman C., Deshpande, C.R., Zaltman, G., 1993. Factors affecting trust in market research relationships. Journal of Marketing 57 (1), 81-101.

Morgan, R.M., Hunt, S.D., 1994. The commitment-trust theory of relationship marketing. Journal of Marketing 58, 20-38.July.

Palmer, J., Bailey, J.P., Faraj, S., 2000. The role of intermediaries in the development of trust on the WWW: the use and prominence of trusted third parties and privacy statements. Journal of Computer Mediated Communication 5 (3).

Pan, X., Ratchford, B.T., Shankar, V., 2001. Why Aren't the Prices of the Same Item the Same at Me.com and You.com?: Drivers of Price Dispersion Among E-Tailers. Working Paper, University of Maryland, College Park, MD 20742.

Pan, X., Ratchford, B.T., Shankar, V., 2002. Price dispersion in online markets be explained by differences in e-tailer service quality?Journal of Academy of Marketing Science30 (4), 433-446.

Pan, X., Shankar, V., Ratchford, B.T., 2002. Price competition between pure vs bricks-and-clicks etailers: analytical model and empirical analysis. Advances in Applied Microeconomics:, Economics of E-Commerce Volume 11 in press.

Pearce, J.L., Branyiczki, I., Bigley, G.A., 2000. Insufficient bureaucracy: trust and commitment in particularistic organizations. Organization Science 11 (2), 148-162.

Ratchford, B.T., Pan, X., Shankar, V., 2003. On the efficiency of internet markets. Journal of Public Policy and Marketing in press.

Rousseau, D., Sitkin, M., Ronals, S.B.S., 1998. Not so different after all: a cross-discipline view of trust. Academy of Management Review 23 (3), 393-404.

Schneiderman, B., 2000. Designing trust into online experiences. Communications of the ACM 43 (12), 57-59.

Shankar, V., Sultan, F., Urban, G.L., Bart, I., 2002. The Role of Trust in Online Customer Support. Working Paper, Sloan School of Management, MIT, Cambridge, MA 02142.

Singh, J., Sirdeshmukh, D., 2000. Agency and trust mechanisms in consumer satisfaction and loyalty judgments. Journal of Academy of Marketing Science 28 (1), 150-167.

Smith, M., Bailey, J., Brynjolfsson, E., 2000. Understanding digital markets: review and assessment. In: Brynjolfsson, E., Kahin, B. (Eds.), Understanding the Digital Economy, MIT Press, Cambridge, MA.

Stewart, K.J., 2003. Trust transfer on the World Wide Web. Organization Science in press.

Sultan, F., Urban, G.L., Shankar, V., Bart, I., 2002. Determinants and Consequences of Trust in eBusiness. Working Paper, Sloan School of Management, MIT, Cambridge, MA 02142.

University of Hong Kong, 2000. Case Trust: Building Third Party e-Tailing Trust. Case 00/95C.

Urban, G.L., Sultan, F., Qualls, W., 2000. Making trust the center of your Internet strategy. Sloan Management Review Fall (1), 39-48. 
Whitener, E.M., Brodt, S.E., Korsgaard,M..A., Werner, J.M., 1998. Managers as initiators of trust: an exchange relationship framework for understanding managerial trustworthy behavior. Academy of Management Review 23 (3), 513-530.

Wicks, A.C., Berman, S.L., Jones, T.M., 1999. The structure of optimal trust: moral and strategic implications. Academy of Management Review 24 (1), 99-116.

Yoon, S.-J., 2002. The antecedents and consequences of trust in online purchase decisions. Journal of Interactive Marketing 16 (2), 47-63.

Zaheer, A., McEvily, B., Perrone, V., 1998. Does trust matter? Exploring the effects of interorganizational and interpersonal trust on performance. Organization Science 9, 141-159.

Zuboff, S., 1982. New worlds of computer mediated work. Harvard Business Review 60 (5), $142-152$. 